\title{
The Effectiveness of Straight Line Walk Application Used on Straight-Walking Skills for Blind Students
}

\author{
Dina Istiqomah Rahayu, Sunardi \\ Universitas Pendidikan Indonesia, Indonesia \\ Email: nardilembang@gmail.com
}

\begin{abstract}
Some studies explore the needs and problems in navigating on the blind person, the ability to walk in a straight line and avoid the tendency to veer. Difficulties that often occur from the tendency to turn is that when traveling straight on the road or open area where environmental information is not good enough to be considered a clue for the visually impaired to help them in maintaining a straight line route. The development of aids for the visually impaired in this era is growing rapidly, both tools to help navigate using global internet-based positioning system and tools to train straight walking using a compass-based system like straight line walks. The purpose of this research is to see the effectiveness of the straight line walk application for visually impaired students walking skills. This research is based on the absence of special attention from the school with the veering phenomenon that occurs in blind students, and its effect which endangers students (such as tripping, crashing into trees, and even walking towards the middle of the highway). This research used the experimental approach with SSR A-B design method. The results showed a decrease in turning distance on the three subjects after being given intervention by using the straight line walk application. Based on the results of this study, it can be concluded that the training program using the straight line walk application can improve the skills of walking straight on blind students.
\end{abstract}

Keywords: straight walking skills, turning tendencies, straight line walk application, visually impaired.

\section{INTRODUCTION}

Blind People in setting themselves associated with surrounding objects, they require three fundamental principles including determining the orientation of where to position themselves to be, knowing the object or area of interest, and realizing how to arrive at a destination. These three principles are obtained through special skill learned in schools that are Orientation and Mobility (O\&M).

Source materials related to walking skills/ navigating the environment on O\&M is called compass direction. According to Rahardja (2017), when students' knowledge and understanding of points of the compass are well controlled, the teacher can proceed to other aspects of the direction, such as walking in a straight line. Straight walking exercises are one of the prerequisites in $\mathrm{O} \& \mathrm{M}$ exercises before the application of larger conceptual materials, such as walking stick techniques. The exercise will be able to help the blind to keep going straight into the open area without feeling worried about unnoticed turns because of the kinesthetic awareness of motoric movement has been honed. Conversely, if the visually impaired are not trained in walking skills, the greatest danger is disorientation due to loss of destination with unfamiliar environmental information when turning occurs unnoticed. It clearly concerns the observable safety issues, because if a person has a tendency to turn a close distance, then that would be a serious problem.
In overcoming the problem of turning tendencies, many researchers are trying to find the causes and solutions to reduce the tendency to turn. One of them is with the use of straight line walk application to practice straight walking skills using voice medium as a guide. Practical use of said application has been tested by Nagy \& Wersényi (2016). The purpose of the study is to test whether the application is able to improve the straight walking skills or not. The results of the study by Nagy \& Wersényi (2016) shows that applications that provide accuracy, sensitivity and target direction may significantly reduce the tendency to turn on a subject whose eyes were closed.

The existence of research conducted by Nagy \& Wersényi (2016) on the aware subject whose eyes are closed to find out the functionality of the tool certainly contributes greatly in the field of developmental science in an effort to improve the skill of walking straight. Therefore, researchers are interested to test whether a straight line walk application can improve the straight walking skills on a blind subject.

\section{METHOD}

At this stage, researchers used a quantitative approach with experimental methods. The experimental research method is "research method used to find the effect of certain treatment on others in controlled condition" (Sugiyono, 2013). 
Figure 1. Research Design in (Barlow et al., 2005)

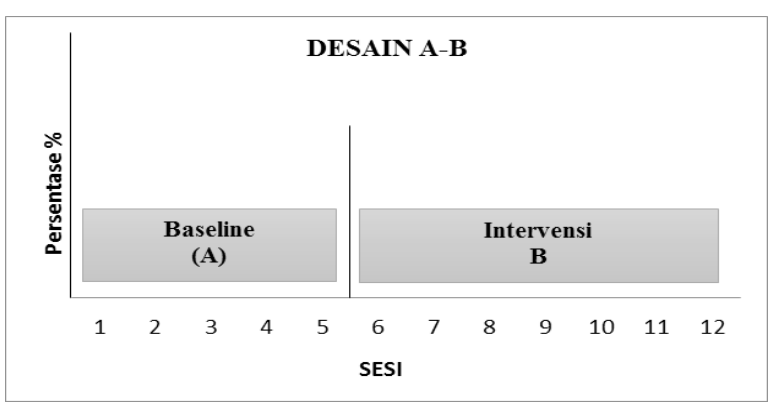

Figure 2. Distance traveled by the subject.



The experimental method used in this research is Single Subject Research (SSR) since this research is done on the single subject. The single subject referred to in the study is the behavior to be changed, is the ability to walk straight on the visually impaired.

Researchers would like to find out the effectiveness of straight line walk apps to improve straight walking skill, so the design used is A-B design (figure 1). Where (A) is the baseline phase prior to the intervention, and (B) is the intervention phase. Each phase will be measured periodically until the obtained data is stable so that when the target behavior is changed it can be assumed that the change is caused by the influence of the independent variable performed during the intervention.

Experiments will be conducted in an open area within the school complex. Distance traveled by the subject to walk straight are $5 \mathrm{~m}, 10 \mathrm{~m}, 15 \mathrm{~m}$, and $20 \mathrm{~m}$. (see figure 2) the variation of distance is intended to explore at what distance a person starts to show a turning tendency and its effect on the intended distance. Analysis of quantitative data in this research is the use of simple descriptive statistics such as a graph. Visual analysis method by using direct observation of the data are presented in the graph (especially the line graph). Line graphs are used to facilitate researchers in explaining subject behavior efficiently and in detail.

\section{FINDING AND DISCUSSION}

\section{Findings}

The following figures present the tendency of ascending direction has the meaning of condition where subjects' trajectory goes worse or the subject veers further, while the downward trend has the meaning of subjects' trajectory conditions improved.

The results of this study indicate that the use of straight line walk applications can improve the skill of walking straight so as to reduce the tendency to veer, especially on the three subjects. Each subject had a varying increase percentage, however, the results of each subject after intervention using a straight line walk application were significantly better than those of baseline. Those results show the use of straight line walk application is effective in practicing the skill of walking straight to blind student.

This study emphasizes the reduction of a tendency to veer so as to improve the skill of walking straight. The word goes straight and veers are two different words, yet have interrelated meanings. Walking straight according to Guth (2007) is a process of moving on a straight line while turning is a deviation from a straightline path experienced by a person. The occurrence of veering is caused by many factors, such as lack of external information, or sources of information so much that all of those factors confused the recipient of information when walking. Furthermore, Wersényi \& Répás (2012) describes the reason for the turn because there is no source of information/guidance to reach the target when walking so that the turn seems unavoidable.

\section{Ability To Walk Straight for Subject 1}

Based on the results of the study, the following findings are thought to be the cause of the blind person veering when walking straight. (1) Lack of kinesthetic awareness in blind people who are accustomed to crossing certain areas/trajectories can be caused by motor motion errors within the walking steps; (2) The tendency of foot position is leaning towards the left or right; (3) Self-perception on the body path is not accurate because they feel they have walked straight; (4) Walking speed, when the turn occurs and the speed goes up, then the distance of deviation will become even farther; (5) The existence of an irrelevant source of information is caught by the visually impaired, for example a straight-line that the blind believed to be facing the highway, so that he seeks clue the of a vehicle sound; (6) The absence of information sources in the form of sunlight contributes to the cause of the turn when walking straight; (7) Lack of intensive O\&M training for the blind. Before the blind person can get on independently, they must first know how they hold themselves and build their relationship with their surroundings (Inman, Loge, \& Cram, 2000). 
Graph 1. As a visual analysis on subject 1, used data presented in graphs below.



Ability To Walk Straight for Subject 2

Graph 2. As a visual analysis on subject 2, used data presented in graphs below.

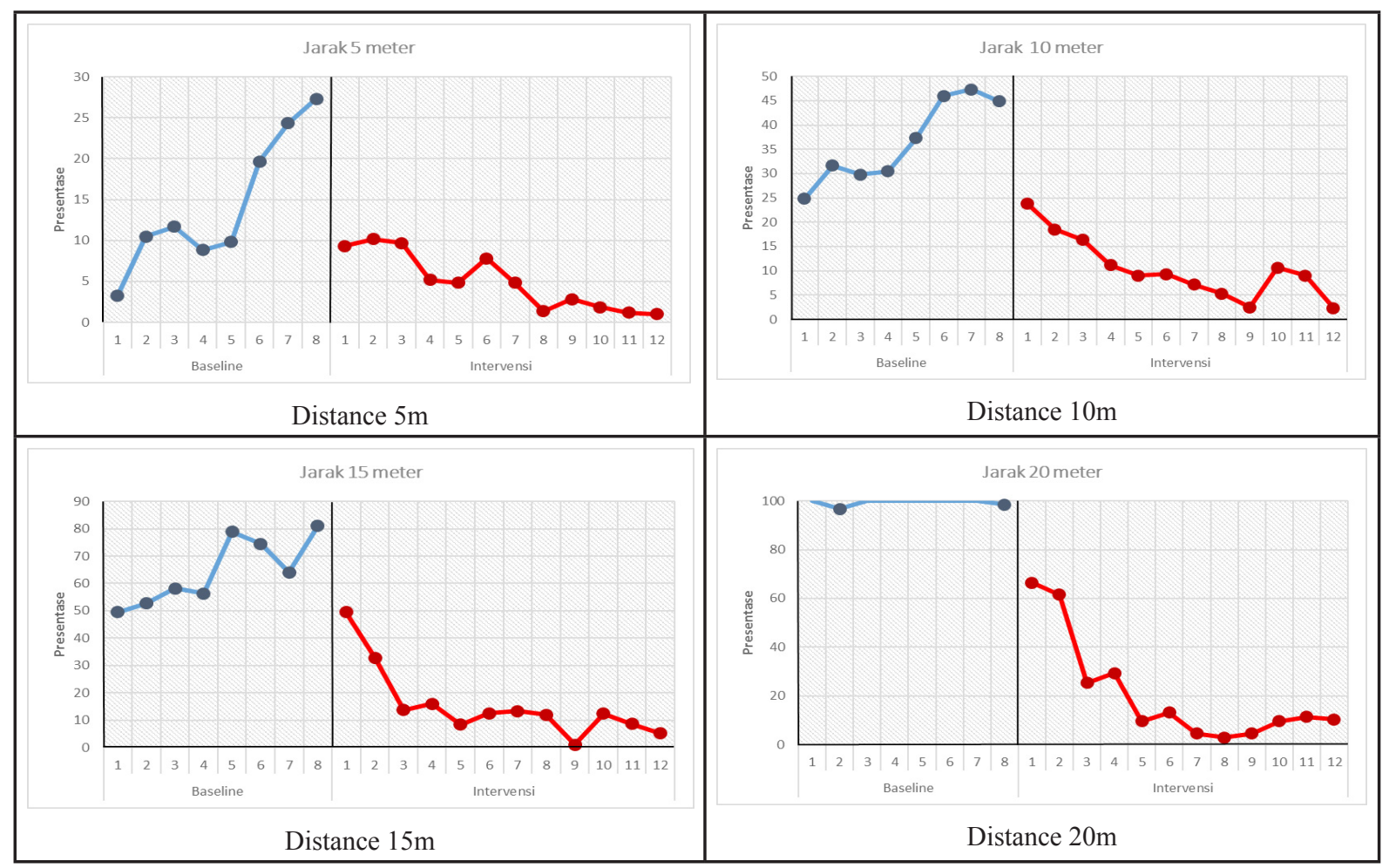




\section{Ability To Walk Straight for Subject 3}

Graph 3. As a visual analysis on subject 3, used data presented in graphs below.

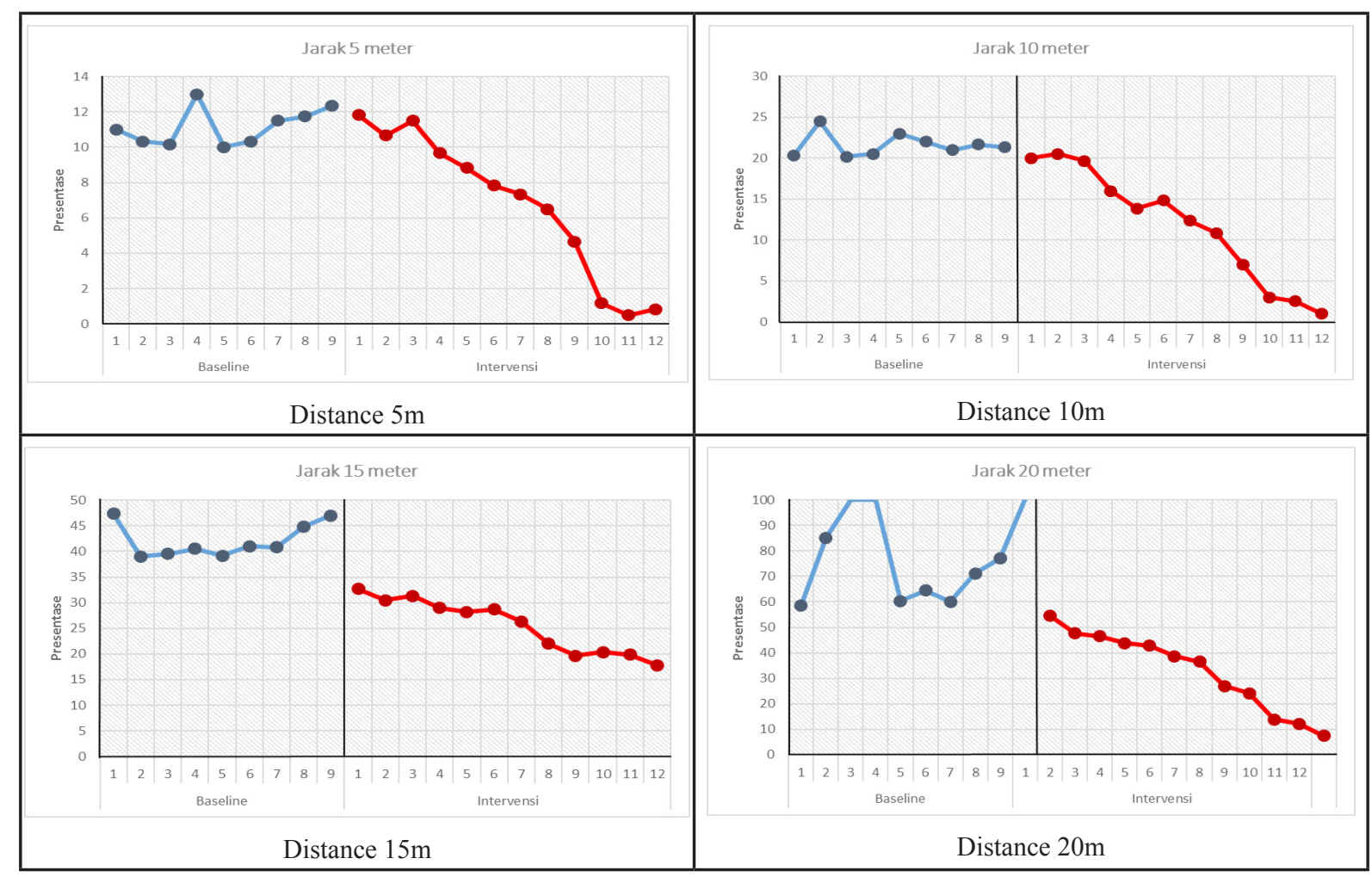

Over the years, various types of electronic aids seem to prevent blind person from being hindered obstacles (ETA: Electronic Travel Aids) (Hoyle 2003) or to help them find their way (EOA: Electronic Orientation Aids) (Denham et al., 2004). According to Roentgen et al. (2009), there are four general ways to improve mobility independently of the blind, with human guides, dog guides, long canes, or electronic travel device.

Blinds fully rely on hearing to understand the environment beyond their reach (Massof, 2003). For example, vehicle sounds are used to determine the crossing location, up to a straight journey across the street (Barlow et al., 2005). The sound characteristics of the vehicle, as well as the surrounding environmental conditions, are estimated to affect detection of different environmental circumstances (Kim et al., 2012). This proves the focus of attention of research subjects in following the vehicle's voice to help them walk straight.

Walking straight is related to the tendency to turn or often known as the veering tendency. Guth (2007) defines the relationship on moving in a straight line and a turn is a deviation from a straight-line path experienced by a person. The turn occurs because there is no source of information/guidance to reach the target when walking so that the turn seems unavoidable. People who walk in unusual terrains with no dependable external information often run in a circle or bend from a straight line. It happens because there is no external focal point, such as mountaintop, sunlight, or moon (Wersényi \& Répás, 2012). Walking straight when vision loss occurs is a known problem, hypothetically it is caused by a motoric fault in the moment of stepping. Without referring to environmental cues like the sun, humans have a tendency to walk in a roundabout.

Blind people have the same problem, so they need to be trained early to walk straight, especially to cross the road while away from the car without getting out of the pedestrian path. The exercise consists of listening to the environment, especially traffic noise, as well as feeling the limits of the sidewalks and roadside (Panëels et al., 2013). Orientation and mobility training (O\&M) represents the formal instruction of navigational skills and is intended to develop strategies to aid orientation, route planning, updating information about one's position, and reorienting to rebuild travel (Panëels et al., 2013).

Whatever the origins of veering the conclusions that can be drawn is the perception of body paths inaccurate because they feel they have walked straight (Boyadjiana et al., 1999). At the same time, the turn is associated with a "forward sense" which can be formed by vestibular input (Bestaven et al., 2012). 


\section{Discussion}

Although the graphs on the SSR method have shown a significant decrease in turning tendencies, the source data coming from the subjects as the direct users of the application's usefulness has not yet been explored. The existence of such data will support the results of research related to the effectiveness of the use of applications to improve the skills to walk straight so that the operational rules in the use of straight line walk applications can be reformulated. The formulation of further research results will demonstrate the straight line walk application as assertive technology in improving the skill of walking straight which does not make the user dependence on the existence of the application, and further implication in O\&M study that is the program-assisted media of straight line walk application can be used as a reference to train the blind in general.

\section{CONCLUSION}

The results of the experiments carried out indicate an effect on the ability to walk straight as a positive target behavior. As outlined in Chapter IV, the use of straight line walk applications in the interventions process shows an improvement in the ability to walk straight to the three subjects, although the quality of each subject's improvement varies. The difference is influenced by several factors such as the imbalance of foot posture, the lack of accurate processing of received external information, and the difference in traveling speed. Nevertheless, each subject showed a significant improvement when viewed based on the scoring in the baseline phase compared to the intervention phase. That result shows the use of a straight line walk application is able to help the visually impaired in improving the skill of walking straight.

Further data retrieval is required after the intervention to the user of straight line walk application as objective data related to the feeling of each subject after the training process using the completed application. The statement will contribute to the formulation of specific operational rules of operation so that the results are expected can be generalizable for the visually impaired person.

\section{REFERENCES}

Barlow, J. M., Bentzen, B. L., \& Bond, T. (2005). Blind Pedestrians and the Changing Technology and Geometry of Signalized Intersections: Safety, Orientation, and Independence. Journal of visual impairment \& blindness, 99(10), 1-13.
Bestaven, E., Guillaud, E., \& Cazalets, J. R. (2012). Is "circling" behavior in humans related to postural asymmetry?. PloS one, 7(9), 1-10.

Boyadjian, A., Marin, L., \& Danion, F. (1999). Veering in human locomotion: the role of the effectors. Neuroscience letters, 265(1), 21-24.

Denham, J., Leventhal, J., \& McComas, H. (2004). Getting from Point A to Point B: A review of two GPS systems. Access World, 4.

Guth, D. (2007). Why does training reduce blind pedestrians veering. Blindness and brain plasticity in navigation and object perception. 353-365.

Hoyle, B. S. (2003). The Batcane-Mobility Aid for the Vision Impaired and the Blind. IEE Symposium on Assistive Technology, 18-22.

Inman, D. P., Loge, K., \& Cram, A. (2000). Teaching orientation and mobility skills to blind children using computer generated $3 D$ sound environments. Georgia Institute of Technology.

Kim, D. S., Emerson, R. W., Naghshineh, K., Pliskow, J., \& Myers, K. (2012). Impact of Adding Artificially Generated Alert Sound to Hybrid Electric Vehicles on Their Detectability by pedestrians Who are Blind. Journal of Rehabilitation Research and Development, 49(3), 381-394.

Massof, R. W. (2003). Auditory assistive devices for the blind. Georgia Institute of Technology.

Nagy, H., \& Wersényi, G. (2016). Comparative evaluation of sighted and visually impaired subjects using a mobile application for reducing veering during blindfolded walking. Acta Technica Jaurinensis, 9(2), 140-157.

Panëels, S. A., Varenne, D., Blum, J. R., \& Cooperstock, J. R. (2013). The Walking Straight Mobile Application: Helping The Visually Impaired Avoid Veering. international Conference on Auditory Display, 6(10), 25-23.

Rahardja, D. (2017). Understanding of Special Teachers in Teaching Children with Special Needs at Inclusive Schools. Journal of ICSAR, 1(1), 1317.

Roentgen, U. R., Gelderblom, G. J., Soede, M., \& de Witte, L. P. (2009). The impact of electronic mobility devices for persons who are visually impaired: A systematic review of effects and effectiveness. Journal of Visual Impairment \& Blindness, 103(11), 743-753.

Sugiyono, S. (2013). Metode Penelitian Pendidikan (Pendidikan Kuantitatif, Kualitatif, dan R\&D). Bandung: Alfabeta.

Wersényi, G., \& Répás, J. (2012). The Influence of Acoustic Stimuli on "Walking Straight" Navigation by Blindfolded Human Subjects. Acta Technica Jaurinensis, 5(1), 3-18. 